\title{
Süper Obez Hastada Laparoskopik Radikal Nefrektomi
}

\author{
Serdar Kalemci, Adnan Şimşir, Burak Turna
}

Ege Üniversitesi, Tıp Fakültesi, Üroloji Anabilim Dalı, İzmir

\section{Giriş}

bezite prevelansının tüm dünyada arttığı bildirilmektedir (1). Sadece Amerika Birleşik Devletleri'nde yaklaşık 35 milyon obez bireyin olduğu tahmin edilmektedir (1-3). Obez bireylerde diabetes mellitus, hipertansiyon, kalp hastalığı ve bazı kanserlerin erken gelişimine yatkınlık bulunmaktadır. Ayrıca obezite, cerrahi girişimler sırasında ve sonrasındaki morbiditeler ve özellikle insizyon yeri komplikasyonları gibi durumlar için potansiyel bir risk faktörü olarak kabul edilmektedir (1-6).

Günümüzde laparoskopik radikal nefrektomi (LRN) lokalize böbrek hücreli kanserlerin tedavisinde standart tedavi seçeneği haline gelmiştir. Daha önceleri obezitenin laparoskopik cerrahi için rölatif bir kontrendikasyon olduğu görüşü kabul ediliyordu. Ancak laparoskopik renal cerrahideki gelişmelerle birlikte; bu cerrahinin hastalardaki onkolojik etklinliği ve hastaların daha çabuk günlük hayatına döndüğünün gösterilmesi nedeniyle, obez hastalar da bu cerrahinin etkinlik alanına grimiştir (3-6).

$\mathrm{Bu}$ olgu sunumunda süper-obez bir hastada $7 \mathrm{~cm}$ renal kitle nedeniyle yapılan laparoskopik radikal nefrektomi operasyonunu sunmayı amaçladık.

\section{Olgu}

Herhangi bir yakınması olmayan 42 yaşında erkek hasta başvurudan 1 ay kadar önce sağ böbrekte saptanan kitlesinin tedavisi için kliniğimize başvurdu. Hikayesinde alt ekstermitede varis, hipertansiyon ve geçirilmiş tonsillektomi öyküsü olan hastanın abdominal operasyon öyküsü yoktu. Hastanın boyu $1.83 \mathrm{~m}$, kilosu 205, vücut kitle indeksi ise $61.2 \mathrm{~kg} / \mathrm{m}^{2}$ olarak hesaplandi. Hemogram ve biyokimyasal parametrelerinde anormal bir bulguya rastlanılmayan hastanın çekilen tüm vücut bilgisayarlı tomografisinde sağ böbrek orta kesim anteriorda egzofitik uzanımı da izlenen $67 \times 58 \mathrm{~mm}$ boyutlarında solid, belirgin kontrast tutulumu gösteren kitle lezyonu saptand 1 (Resim 1).

Genel anestezi uygulaması ve 18 Fr Foley sonda yerleştirilmesini takiben hasta sağ $60^{\circ}$ flank pozisyonuna alındı (Resim 2). Krista iliaka ile umblikus arasındaki alanda rektus

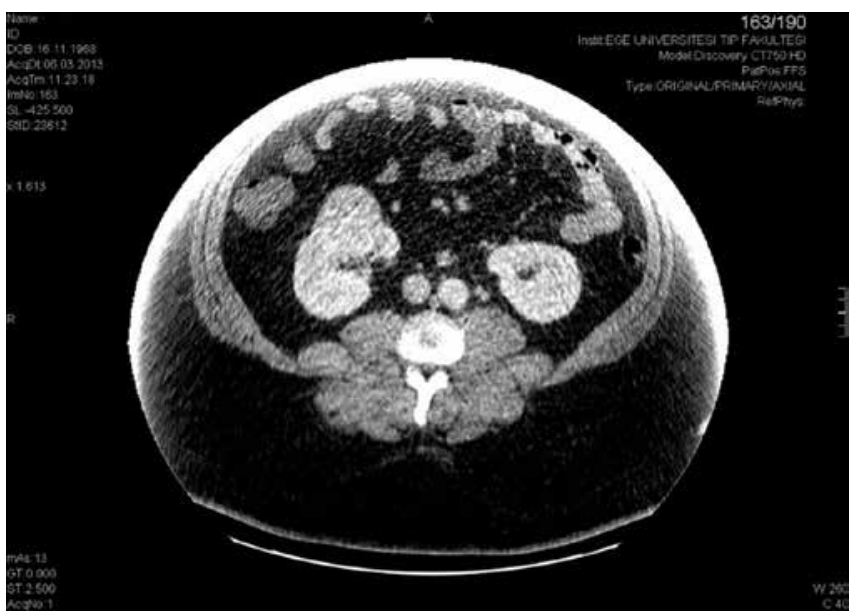

Resim 1

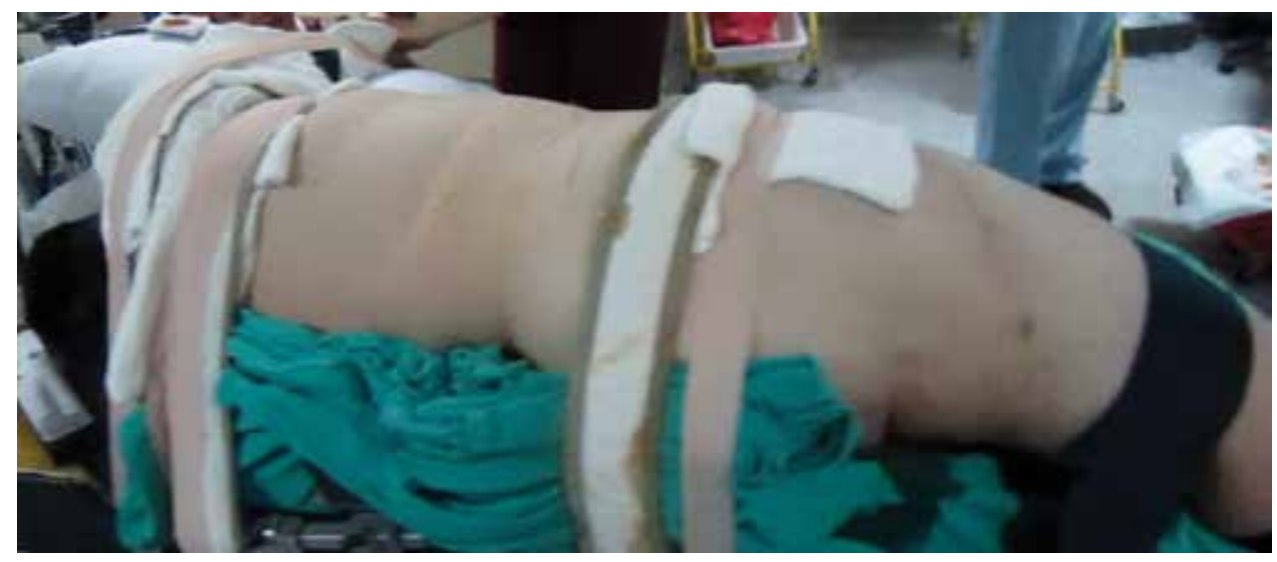

Resim 2 


\section{SÜPER OBEZ HASTADA LAPAROSKOPIK RADIKAL NEFREKTOMI}

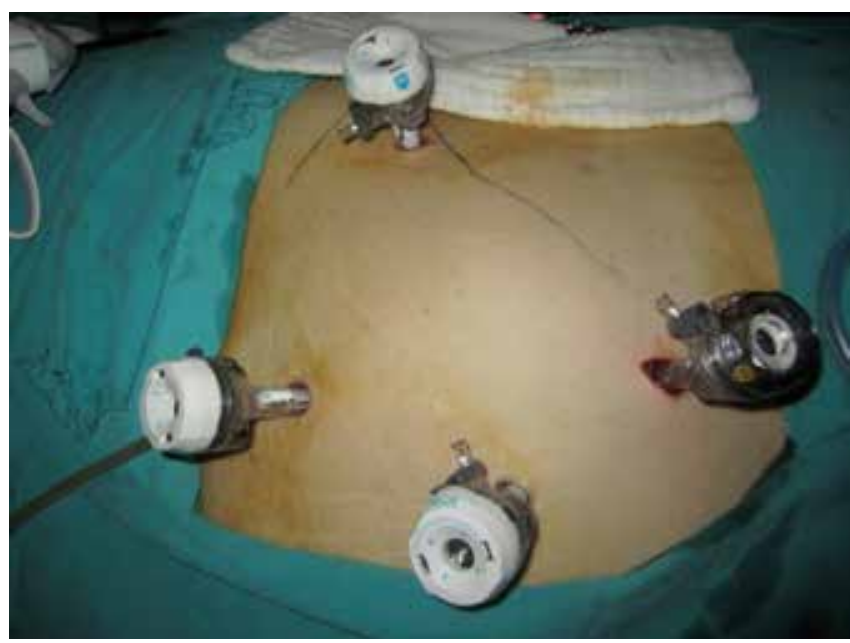

Resim 3

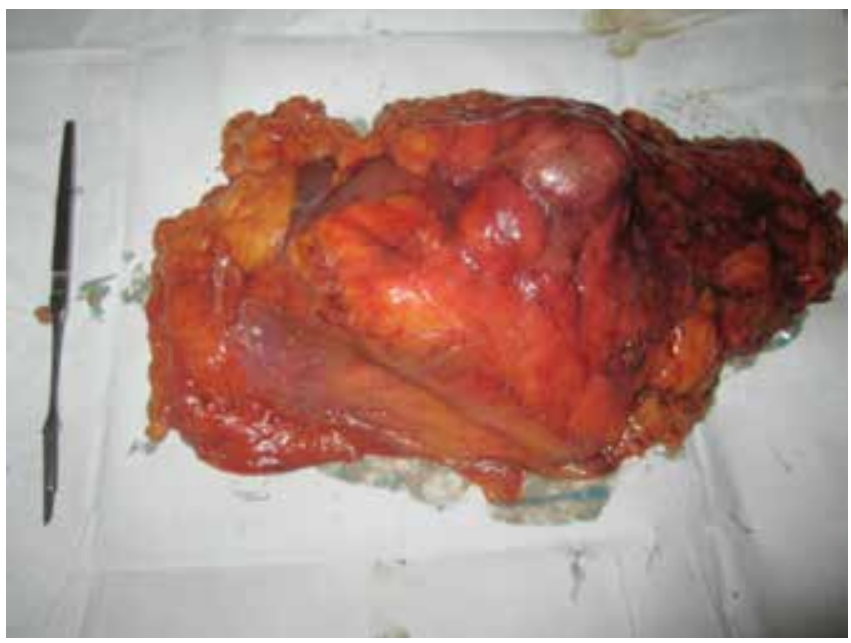

Resim 5

kası lateralinden Veress iğnesi ile batına girilerek pnömoperitoneum sağlandı ve ilk ekstra-long trokar yerleştirildi. Otuz derece optik ile inspeksiyonda batın içi adipoz dokunun ileri derece fazla olduğu ve batında herhangi bir ciddi adhezyonun olmadığı görüldü. Daha sonra direkt görüş eşliğinde ikinci trokar rektus kası laterali hizasında kostal sınırın $2 \mathrm{~cm}$ altına yerleştirildi. Üçüncü trokar orta hatta umblikusun 3 $\mathrm{cm}$ lateral hizasında girildikten sonra böbreğin lateral retraksiyonu için aksiller hat hizasında dördüncü trokar yerleştirildi (Resim 3). Toldt çizgisi insize edilip inen kolon mobilizasyonu sonrası mezokolon ile Gerota fasyası arasındaki alana girilerek gonadal ven ve üreter bulunup çevre dokulardan serbestleştirildi. Gonadal ven ve üreter askıya alınıp kranial yönde takip edilerek renal hilusa doğru diseksiyon planı geliştirildi. Böbrek alt polü serbestleştirildikten sonra perirenal yağ dokusu ve Gerota fasyası laterale doğru ekarte edilip renal damarlar ortaya konuldu (Resim 4). Renal arter ve ven çevre dokulardan serbestleştirildikten sonra, önce arter daha sonra ven hemo-clip ile klempe edildikten sonra transekte edildi. Böbrek üst polü ve laterali çevre dokulardan tamamen ayrıldı. Üreter distale doğru disseke edilerek hemoclip ile klempe edilerek transekte edildi. Böbrek organ torbasına

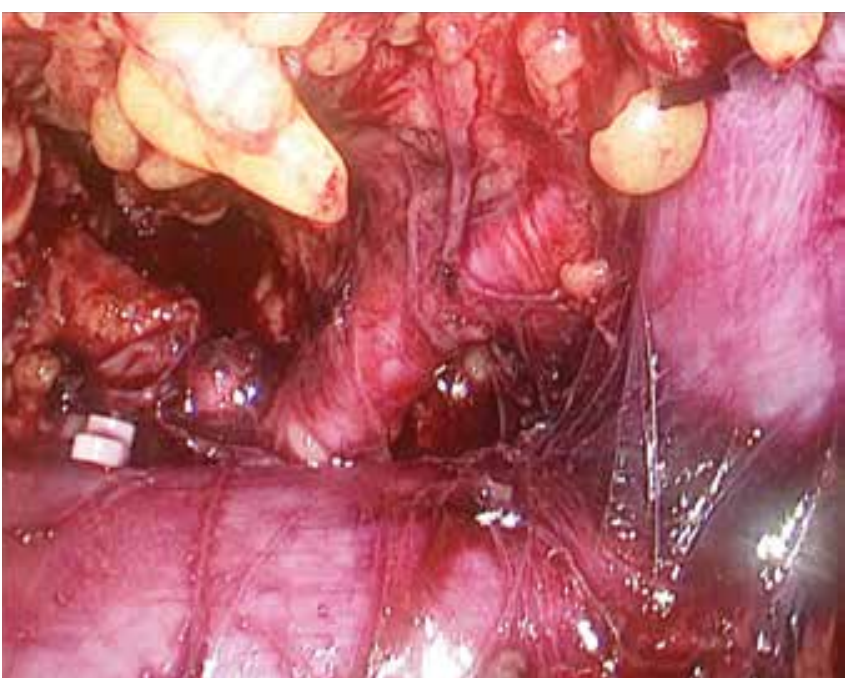

Resim 4

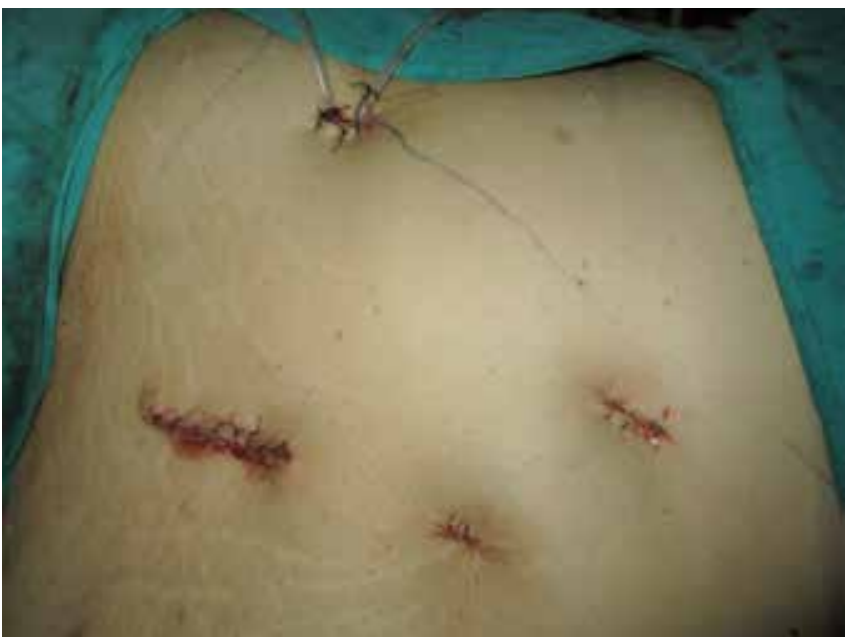

Resim 6

konulduktan sonra spesmenin çıkarıldığ 1 trokar yeri hariç diğer yerlerin fasyaları Carter Thomason iğnesi yardımı ile 0 Vicyrl süturla kapatıldı. Retroperitoneal alana iki adet dren konulduktan sonra spesimen morsele edilmeden intakt biçinde ilk trokarın giriş yeri genişletilerek vücut dışına çıkarıldı (Resim 5). Bu yerin fasyası ve diğer trokar giriş yerleri anatomiye uygun olarak kapatılarak operasyon sonlandırıld (Resim 6). Toplam operasyon süresi 125 dakika, tahmini kan kayb1 50-60 ml idi. Operasyon sirasında ve postoperatif erken dönemde hastada herhangi bir komplikasyon izlenmedi.

Postoperatif 2. günde sondası ve drenlerinden birisi çekilen hastanın drenajı olmaması üzerine operasyonun 5. günü diğer dreni alındı ve hasta 7 . günde taburcu edildi. Spesimenin patolojik incelemesi cerrahi sınırı negatif berrak hücreli tip böbrek kanseri olarak rapor edildi.

\section{Tartışma}

Obezitenin kişiler için önemli bir sağlık problemi olmasının yanında cerrahlar için de önemli bir sorun oldukları her cerrah tarafından bilinen bir gerçektir. Laparoskopik cerrahinin yeni yeni geliştiği dönemlerde yapılan tartışmalarda bu 
yöntemin açık cerrahiye göre morbiditesinin daha yüksek olduğu görüşleri hakimken, artan cerrahi deneyim ile kısalan operasyon süreleri sonucunda durumun hiç de böyle olmadığının farkına varılmıştır (7-9). Laparoskopik cerrahinin sadece kozmetik avantajlarının olmadığı, erken iyileşme, daha az post operatif ağrı, daha az kanama ve daha az işgücü kaybı gibi pekçok avantajının olduğu artık tartışılmayan bir gerçektir. Durum bu haldeyken "sayısı gittikçe artan obez hastalara yaklaşımda bir farklılık gerekecek mi?" sorusunun yanıtı da bilimsel alanda yavaş yavaş netleşmeye başlamıştır. $\mathrm{Bu}$ hasta grubunda yapılması gereken şüphesiz minimal invaziv cerrahiyi tercih etmektir. Buradaki en büyük sorun ise teknik ekipman farklılığı olacaktır. Öyle ki yukarıda sunumu yapılan hastanın portları için üretici firmalarla görüşülerek portlar ekstra çabalar sonucunda elde edilmiştir. Çok daha basiti ise yurdumuzda kullanılan pek çok operasyon masasının taşıma kapasitesinin maksimum 130-160 kilo olmasidir.

Literatür verileri incelendiğinde obez hastaların tıpkı obez olmayanlarda olduğu gibi gerek operasyon öncesi gerekse operasyon sırasında ve sonrasında komplikasyon oranlarında laparoskopik ve açı cerrahi ile tedavi edilmeleri arasında fark izlenmemektedir. Ancak obez hastalarda tıpkı diğer maligniteler gibi böbrek hücreli karsinom gelişme sıklığında da anlamlı derecede artışın saptanması bu grup hastalarla her cerrahın gün geçtikçe daha çok karşılaşacağ sonucunu doğurmaktadır (8-15).

Ayrıca ulaşılan literatür verileri incelendiğinde yaklaşık aynı BMI'ya sahip bir hastanın Japonya' da "El yardımlı laparoskopiyle" parsiyel nefrektomi olduğu bunun dişında süper obez hastada böbrek cerrahisi ile ilgili verinin olmadığ görülmüştür (16).

\section{Sonuç}

Obez hastalarda böbrek malignitesi görülme sıklı̆̆ı giderek artmaktadır. Bu hastalara minimal invaziv yaklaşımla ilgili, cerrahların kafasında pek az soru işareti kalmıştır. Ancak süper-obez hastalarla ilgili literatürde bilimsel verinin neredeyse hiç olmaması yaklaşım konusunda çekincelere neden olmaktadır. Bununla birlikte yukarıda sunulan hastanın tedavisinde hiçbir sorun ile karşılaşılmaması bizlere cesaret vermiştir.

\section{Kaynaklar}

1. Mokdad AH, Ford ES, Bowman BA, et al. Prevalence of obesity, diabetes and obesity - related health risk factors, 2001. JAMA 2003; 289: 76-77.

2. Calvert RC, Burgess NA. Urolithiasis and obesity: metabolic and technical considerations. Curr Opin Urol 2005; 1 5: 113-117.

3. Doublet J, Belair G. Retroperitoneal laparoscopic nephrectomy is safe an effective in obese patients: A comparative study of 55 procedures. Urology 2000; 56: 63-66.

4. Xu M, Gill IS. Laparoscopic partial nephrectomy in obese patients. Urology 2007; 69: 44-48.

5. Romero FR, Rais-Bahrami S, Muntener M, Brito FA, Jarrett TW, Kavoussi LR. Laparoscopic partial nephrectomy in obese and non-obese patients: comparison with open surgery. Urology 2008; 71: 806-809.

6. Gong EM, Orvieto MA, Lyon MB, Lucioni A, Gerber GS, Shalhav AL. Analysis of impact of body mass index on outcomes of laparoscopic renal surgery. Urology 2007; 69: 38-43.

7. Eaton SH, Thirumavalaven N, Katz MH, Babayan RK, Wang DS. Effect of body mass index on perioperative outcomes for laparoscopic partial nephrectomy. J Endourol 2011; 25: 1447-1450.

8. Naeem N, Petros F, Sukumar S, et al. Robot-assisted partial nephrectomy in obese patients. J Endourol 2011; 25: 101-5.

9. Cha EK, Lee DJ, Del Pizzo JJ. Current status of robotic partial nephrectomy (RPN). BJU Int 2011; 108: 935-941.

10. Higgins JP, Thompson SG, Deeks JJ, Altman DG. Measuring inconsistency in meta-analyses. BMJ 2003; 3 27: 557-560.

11. Casp-uk.net. National Health Service's Critical Appraisal Skills Programme (CASP) CASP International Network (CASPin) 2010. Available at: http://www.casp-uk.net/. Accessed December 2011.

12. Pierorazio PM, Patel HD, Feng T, Yohannan J, Hyams ES, Allaf ME. Robotic-assisted versus traditional laparoscopic partial nephrectomy: comparison of outcomes and evaluation of learning curve. Urology 2011; 78: 813-819.

13. Liberati A, Altman DG, Tetzlaff J, et al. The PRISMA statement for reporting systematic reviews and metaanalyses of studies that evaluate healthcare interventions: explanation and elaboration. BMJ 2009; 339.

14. Dindo D, Demartines N, Clavien PA. Classifi cation of surgical complications:a new proposal with evaluation in a cohort of 6336 patients and results of a survey. Ann Surg 2004; 240: 205-213.

15. Jacobs SC, Cho E, Dunkin BJ, Bartlett ST, Flowers JL, Jarrell B. Laparoscopic nephrectomy in the markedly obese living renal donor. Urology 2000; 56: 926-929.

16. Yokoyama $H$, Saito $T$, Suzuki $T$, Yamagishi $T$, Inoue $\mathrm{H}$, Ishizuka O, Nishizawa O. A case of hand-assisted laparoscopic radical nephrectomy in a severely obese patient (body mass index: 62.6). Hinyokika Kiyo. 2013 Apr;59(4):231-234.

Yazışma Adresi:

Adnan Şimşir

Ege Üniversitesi, Tıp Fakültesi, Üroloji Anabilim Dalı, Izmir

Tel: +905333364354

e-mail: simsiradnan@hotmail.com 